\title{
Protective effect of CoQ10 and Artemisia sieberi combination on PC12 cells model of 6-hydroxydopamine induced toxicity
}

\author{
Seyed Behnamedin Jameie ${ }^{1}$, Mona Farhadi ${ }^{2 *}$ iD, Kamelia Gharibzad ${ }^{2}$ \\ 1. Neuroscience Research Center, Iran University of Medical Sciences, Tehran, Iran \\ 2. Department of Microbiology, Karaj Branch, Islamic Azad University, Karaj, Iran
}

\begin{abstract}
Introduction: Parkinson's disease (PD) is a progressive neurodegenerative disease that affects motor function. The etiology of PD is unknown and routine therapies temporarily relieve the symptoms. Neuroprotective based therapies preserve the remaining neurons and prevent the progression of PD. Artemisia sieberi has anticancer and neuroprotective effects. The $\mathrm{CoQ}_{10}$ also is an antioxidant that has proven anti-inflammatory and antioxidant properties. In order to study the effect of Artemisia and $\mathrm{CoQ}_{10}$ on the PD cellular model, the present research was designed.
\end{abstract}

Methods: PC12 cells were treated with different concentrations of 6hydroxydopamine. Then the cells divided into the control (cells were not treated), DMSO group and experimental groups treated with the different concentrations of Artemisia sieberi extracts, $\mathrm{CoQ}_{10}$ and combination of them for $24 \mathrm{~h}$. The viability of the cells, reactive oxygen species (ROS) generation and p53 expression were evaluated.

Results: Artemisia at a concentration of $200 \mu \mathrm{g} / \mathrm{ml}$ and $\mathrm{CoQ}_{10}$ at a concentration of $75 \mu \mathrm{g} / \mathrm{ml}$ significantly increased cell viability in the treated groups after $24 \mathrm{~h}$. Their combination showed better and more significant results compared to each alone. Hoechst staining showed significantly reduced apoptosis in treated cells. ROS generation reduced in the treated groups with better results for the combinationtreated groups. The same results acquired for the expression of P53 in the treated cells.

Conclusion: Regarding the results of both Artemisia and $\mathrm{CoQ}_{10}$, it could be concluded that they act synergistically with possible similar pathways. Although the Artemisia itself showed significant results, it seems that the combination method might have more therapeutic effects.

http://dx.doi.org/10.32598/ppi.24.4.80

\section{Keywords:}

Parkinson's cell model;

Artemisia sieberi;

$\mathrm{CoQ}_{10}$;

Apoptosis

* Corresponding author:

M. Farhadi

Email:

mona.farhadi@kiau.ac.ir

Tel: +98 (912) 2467389

Received 17 December 2019;

Received in revised form 26

July 2020; Accepted 4 August

2020

\section{Introduction}

Parkinson's disease (PD) is an age-dependent neurodegenerative disease that results in the death of dopaminergic neurons in the substantia nigra and 
reduced dopamine levels lead to a series of symptoms, especially motor disorders (Henchcliffe and Beal, 2008). PD affects $1 \%$ of people over the age of 65 , and the incidence of this disease in males is more than females (Hirtz et al., 2007). Due to increased oxidative factors in the environment, the risk of developing neurodegenerative diseases is increasing (Cameán et al., 2013). The treatment of PD still remains unsuccessful; consequently, taking appropriate therapies or prophylactic procedures is necessary to prevent or postpone the onset of it. On the other hand, pharmacological and conservative treatments can only relieve the symptoms of the disease (Lipski et al., 2011). Surgery, cell therapy and gene therapy are also very risky and costly. The progressive nature of the disease and the development of severe disabilities in the late stages of the disease and the increasing prevalence of PD has become an important medical problem, which has not yet been treated with effective therapies or methods of prevention. In studies conducted with antioxidant and anti-apoptotic herbs, it has been proven that the neuroprotective based therapies maintain the remaining neurons and stop the progression of the disease (Singh et al., 2007). Among all the therapeutic methods, traditional medicine has recently achieved remarkable results based on the use of herbal medicines. The side effects and cost of using herbal drugs are lower than those of chemical origin. Recently, lots of attention has been paid to the role of various plants with therapeutic applications. Artemisia, known in Iran as the Artemisia (Artemisia sieberi) plant, is from the family of the Asteraceae (Gordanian et al., 2014) herbaceous plant, which is native Siberian species in the north. The use of the Artemisia plant for the treatment of some diseases goes back to ancient times. Artemisia family is used as the most important medicinal plant in the treatment of many diseases, including malaria, diarrhea, etc. in the world. These plants have antioxidant properties, are used in pharmaceutical applications. The medicinal properties of this plant are related to its evaporating essences, which include a range of active chemicals, such as terpenes (monoterpenes, sesquiterpenes, diterpenes, artemisinin) as well as flavonoids and polyphenols. The importance of the Artemisia genus is due to the presence of a sesquiterpene called artemisinin, which is used to treat malaria. In addition to artemisinin, another compound called $\beta$ caryophyllene, which has anti-inflammatory and anticancer properties and can be used as a local anesthetic. Artemisia also has antispasmodic and anticonvulsant effects (Gordanian et al., 2014). The study of the protective effects of artemisinin on oxidative stress and brain damage, as well as cerebral ischemic, the damage was carried out by Bora and Sharma (2010). According to their observations, pre-treatment with Artemisia extract reduces the tissue- injury induced by cerebral infarction. Muto et al. (2003) studied the toxic dose of Artemisia, they showed some changes in hematological and biochemical properties in mice exposed to Artemisia. By analyzing the antioxidant compounds in Artemisia sieberi, Mojarab et al. (2009) showed that the flavonoids and anthocyanin in Artemisia sieberi are high and the high levels of these compounds are effective in reducing the oxidative stress. By investigating Artemisia vulgaris, Lee et al. (2000) reported effective phenolic compounds in the plant and the inhibitory effect on monoamine oxidase. The use of natural antioxidants plays an important role in preventing the formation of free radicals and preventing diseases. Among well-known antioxidants with therapeutic effects, the $Q_{10}$ coenzyme as a mitochondrial enzyme plays an important role in the electron-transfer of the respiratory cell cycle, which has attracted enormous interest. The $\mathrm{CoQ}_{10}$ interferes with the protection of membrane and cellular molecules as a therapeutic agent in certain diseases, especially neurodegenerative diseases. Jameie et al. (2014) reported the combined therapeutic effects of low-level laser therapy and $\mathrm{CoQ}_{10}$ on the treatment of neuropathic pain in rats. Regarding the role of oxidative stress in PD and the neuroprotective and antioxidant properties of Artemisia and $\mathrm{CoQ}_{10}$, the present research was designed to evaluate the effects of $\mathrm{CoQ}_{10}$ and Artemisia combination treatment on a cellular model of PD induced by 6-hydroxydopamine (6-OHDA) in PC12 cell line.

\section{Materials and methods}

\section{Reagents}

The PC12 cell line was purchased from the Iran pastor institute. FBS and DMEM (Gibco), 6-OHDA (Sigma), dimethyl sulfoxide (Sigma), Hochest 33342 (Sigma), dichlorofluorescein (DCF, Sigma) and P53 
(Abcam) were used in this study.

\section{Artemisia extraction}

Extracting the Artemisia sieberi plant was carried out by soaking. The $10 \mathrm{~g}$ of Artemisia sieberi plant was soaked with $200 \mathrm{ml}$ of $80 \%$ ethanol for 2 days. The contents were filtered by filter paper. The solution was transferred to a rotary machine to remove the ethanol solvent. The solution was rotated at $40^{\circ} \mathrm{C}$ and 279rpm. The concentrated extract appeared as a dark-colored paste fluid in the bottom of the balloon and was placed in a foam machine at a temperature of $40-30^{\circ} \mathrm{C}$ after extraction to dry completely.

\section{Cell culture}

PC12 cells were cultured in flasks containing RPMI medium and $10 \% \mathrm{FBS}, 100 \mathrm{U} / \mathrm{ml}$ penicillin, and $100 \mu \mathrm{g} / \mathrm{ml}$ streptomycin under 5\% CO2 and 95\% humidity at $37^{\circ} \mathrm{C}$ temperature. Once a monolayer is formed, it passages and then after three passages were used for experiments.

\section{Treatment}

In this study, the cells were treated with different concentrations of 6-OHDA dissolved in DMSO (25, $50,75,100$ and $125 \mu \mathrm{M}$ ) for $24 \mathrm{~h}$. The experimental groups consisted of control (without treatment), 6-

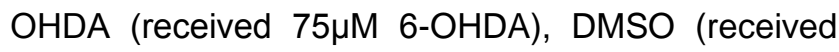
DMSO) and experimental groups with different concentrations of Artemisia sieberi extracts (200, $400,600,800$ and $1000 \mu \mathrm{g} / \mathrm{ml}), \mathrm{CoQ}_{10}$ concentrations $(25,75,100,150,200$ and $250 \mu \mathrm{g} / \mathrm{ml})$ and their combinations $\left(\mathrm{CoQ}_{10} 75+\right.$ Artemisia200, $\mathrm{CoQ}_{10} 100+$ Artemisia400 and $\mathrm{CoQ}_{10} 150+$ Artemisia600) at 24h.

\section{Viability assay}

The 5000 cells were cultured in 96-well plates and placed in an incubator for 1 day. After the cells adhered to the plate, all wells were treated with 6OHDA for $24 \mathrm{~h}$ except for negative control and the sham group. Then the treatment was performed with CoQ10, Artemisia sieberi and combination then incubated. After incubation time, $100 \mu \mathrm{l}$ MTT $(5 \mathrm{mg} / \mathrm{ml}$ in PBS to a final concentration of $0.5 \mathrm{mg} / \mathrm{ml}$ ) was added to the wells and plate incubated for $2-4 \mathrm{~h}$, then $100 \mu \mathrm{l}$ DMSO was added and the plate was read by an ELISA reader (BioTek, ELx800, USA) at 570nm wavelength. The following formula was used to convert optical absorption into the percentage of viable cells:

$$
\% \text { viable cells }=\frac{\left(a b s_{\text {sample }}-a b s_{\text {blank }}\right)}{\left(a b s_{\text {control }}-a b s_{\text {blank }}\right)} \times 100
$$

\section{Reactive oxygen species (ROS)}

This technique was used to evaluate the production of free radicals. The cells were cultured in 6-well plates and then washed once with PBS after 24h. Then, $0.4 \mathrm{mg}$ of DCF powder in $1 \mathrm{ml}$ DMSO was dissolved and diluted with PBS. Subsequently, subsequently, $1 \mathrm{ml} \mathrm{DCF}$ was added to the wells in the dark for $30 \mathrm{~min}$. After washing with $1 \mathrm{ml}$ PBS, it was read with a microplate reader fluorescence measurements were made using a citation 3 imaging reader (BioTek Instruments) set to $37^{\circ} \mathrm{C}$. Measurements were made using a 485/20 excitation and a 528/20 emission filter pair and a PMT sensitivity setting of 55 .

\section{Hoechst staining}

To Hoechst stain preparation $(0.2 \mathrm{mg}$ of powder stain in $1 \mathrm{ml}$ distilled water) was dissolved and filtered through the syringe filter. All procedure was done in the dark. The cells were first cultured in a 24-well plate. The number of cells in each well was considered to be 30,000 cells and after treatment with the mentioned concentrations, the culture medium was evacuated and the cells were washed 2 times with PBS. The cells were then fixed with $4 \%$ paraformaldehyde for 20-30min and brought out from fixative. The cells were again rinsed with PBS and stained with Hoechst. The detection of the apoptotic cell nucleus was evaluated by an inverted fluorescence microscope model (IM-3FL4) at $357 \mathrm{~nm}$ excitation and $447 \mathrm{~nm}$ emission wavelengths, respectively. The treatment was repeated three times, for each group 5 slides were prepared and each slide was counted into 5 zones (Shah et al., 2014).

\section{Western blotting}

PC12 cells were cultured in 96 well plates $(3.0 \times 105 /$ well) and treated with CoQ10 and Artemisia combination and alone. After incubation, cells were collected and lysed in a buffer containing $50 \mathrm{mM}$ HEPES (pH 7.4), $150 \mathrm{mM} \mathrm{NaCl}, 0.1 \%$ Triton X-100, $1.5 \mathrm{mM} \mathrm{MgCl} 2, \quad 1 \mathrm{mM}$ EDTA, $2 \mathrm{mM}$ sodium orthovanadate, $4 \mathrm{mM}$ sodium pyrophosphate, $100 \mathrm{mM}$ 


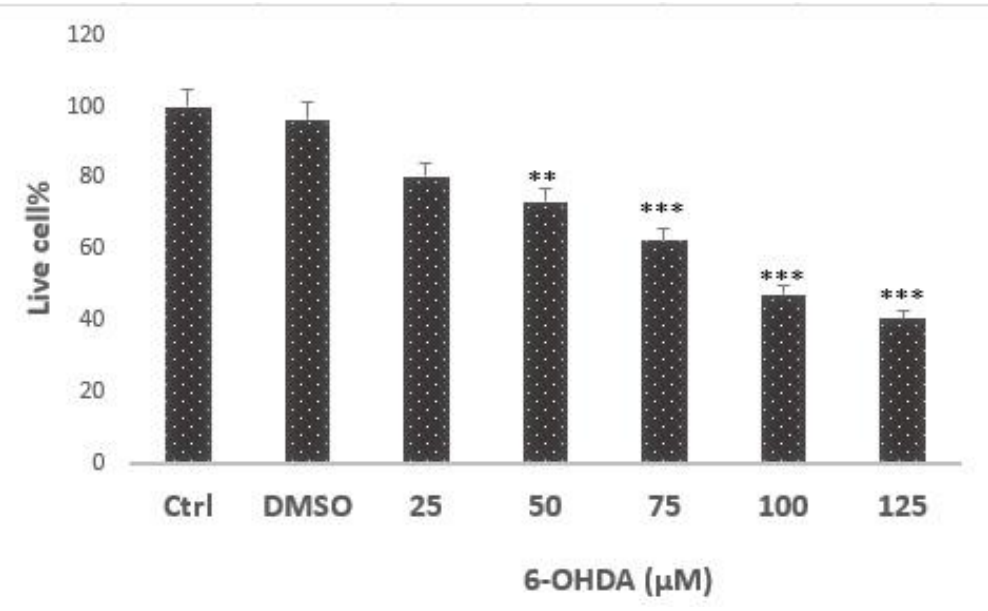

Fig.1. The viability of the PC12 cells treated by 6-hydroxydopamine (6-OHDA) after $24 \mathrm{~h}$. All experiments were performed in triplicate and data as mean \pm SEM. ${ }^{* * *} P<0.001,{ }^{* *} P<0.01$ compared to the control groups.

$\mathrm{NaF}$ and protease inhibitor mixture (1:500; SigmaAldrich) for cell lysates. Then by $10 \%$ SDSpolyacrylamide gel (Invitrogen) electrophoresis was performed and transferred onto polyvinylidene fluoride membranes. The membranes were subsequently probed with antibodies, including rabbit polyclonal P53 (ab226419) and mouse monoclonal $\beta$ actin antibody (1:10,000; ab6276) from Abcam (Cambridge, MA, USA). The p53 antibody was added to the membrane. A secondary antibody was added onto the membrane within $24 \mathrm{~h}$ so that the entire surface of the membrane was covered. The membrane container and secondary antibodies were placed on a slow-moving pad at ambient temperature for an hour. After the incubation time, the secondary antibodies were removed and then washed by TBS buffer for 3 to $10 \mathrm{~min}$ and bands were evaluated. Densitometry analyses of bands were adjusted against $\beta$-actin, which functioned as a loading control. The percentage increase or reduction in protein expression levels was estimated by comparison to DMSO control. Experiments were performed in triplicate, separately (Li et al., 2005).

This research has been approved by the ethics committee of Neuroscience Research Center of Iran University of Medical Sciences with code 946 / P1/ 94

\section{Statistical analysis}

The results were analyzed by SPSS software using One Way ANOVA. To evaluate the normal distribution of data, the Kolmogorov-Smirnov test was used and to evaluate the equivalence of variances, the Levin test was also used. To compare the mean of the groups, Tukey's post hoc test was used and a
$P<0.05$ was considered statistically significant.

\section{Results}

\section{Viability assay results}

The viability outcomes of the various concentrations of 6 -OHDA $(25,50,75,100$ and $125 \mu \mathrm{M})$ after $24 \mathrm{~h}$ are shown in Figure 1. Consequently, $75 \mu \mathrm{M}$ showed a $50 \%$ significant decrease in the vital capacity of the cells $(P<0.01)$. Thus, an effective concentration of $75 \mu \mathrm{M}$ was considered for the induction of Parkinson's. Also, the results of this test determined the suitable time for the function of 6-OHDA on the cell line at $24 \mathrm{~h}$. Therefore, this dose and time were used to continue the study.

The viability of cells $24 \mathrm{~h}$ after incubation with 6OHDA and various concentrations of $\mathrm{CoQ}_{10}$ is shown in Figure 2. All $\mathrm{CoQ}_{10}$ 75, 100, 200 and $250 \mu \mathrm{M}$ concentrations showed a significant increase compared with the 6-OHDA cells $(P<0.001)$. The number of live cells at the $75 \mu \mathrm{M}$ concentration was a more significant increase compared to other concentrations.

The viability results of Artemisia treatment in 6-OHDA treated cells showed that all concentrations had a significant positive correlation with the control group $(P<0.01)$. The $200 \mu \mathrm{g} / \mathrm{ml}$ concentration of Artemisia showed a more significant increase in the number of living cells compared to 6-OHDA cells and other concentrations $(P<0.01)$. Also, the results showed that there was no significant difference between the $1000 \mu \mathrm{g} / \mathrm{ml}$ concentration compared to the $6-$ OHDA cells, but decreased significantly $(P<0.05)$ compared to the control and DMSO (Fig. 3).

The results of the combined concentrations of 


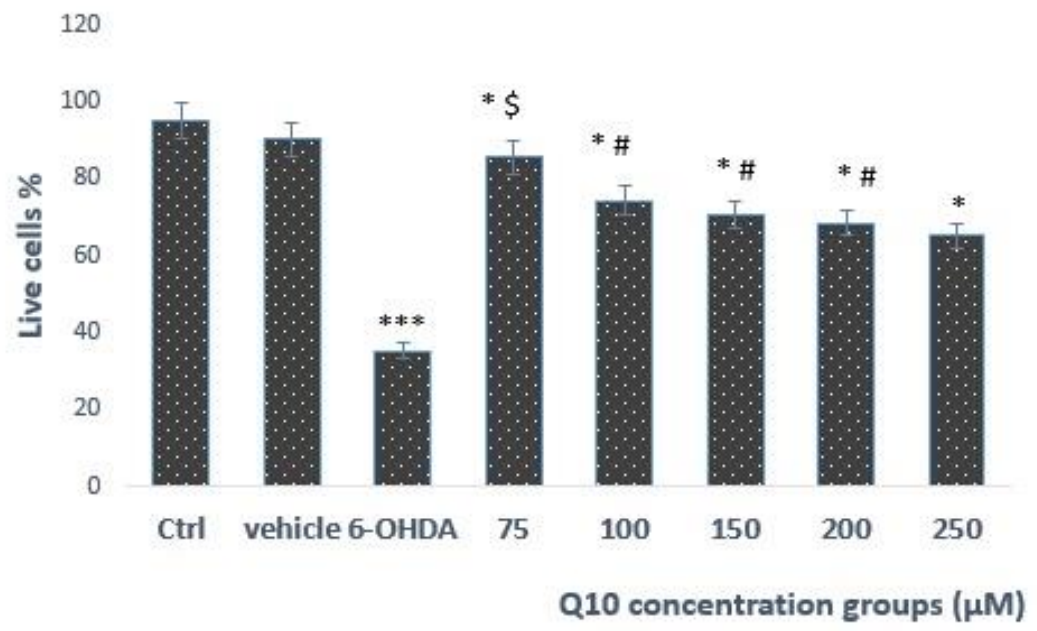

Fig.2. The viability of 6-hydroxydopamine (6-OHDA) treated cells with different concentrations of Q10 after 24h. All experiments were performed in triplicate and data as mean \pm SEM. ${ }^{* * *} P<0.001$ significant decreased with control; ${ }^{\#} P<0.001$ significant increased with the $6-\mathrm{OHDA} ;{ }^{\$} P<0.01$ significant differences with the other concentrations.

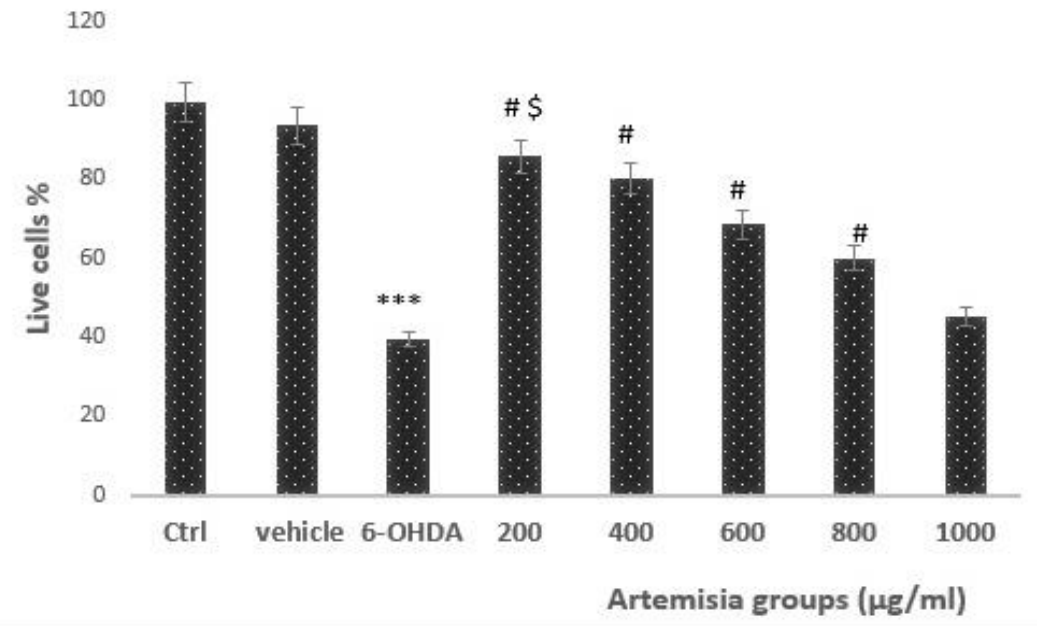

Fig.3. Comparison of the viability of 6-hydroxydopamine (6-OHDA) treated cells with different concentrations of Artemisia sieberi after $24 \mathrm{~h}$. All experiments were performed in triplicate. ${ }^{\#} P<0.01$ significant increase compared with the 6-OHDA cells; ${ }^{\$} P<0.05$ significant increase between 200 with other concentrations; ${ }^{* * *} P<0.001$ significant decreases of treated cells compared with the DMSO and control.

Artemisia sieberi and $\mathrm{CoQ}_{10}$ are shown in Figure 4. The combined concentration of $\left(\mathrm{CoQ}_{10} 75+\right.$ Artemisia200), (CoQ 10 100+ Artemisia400) and $\left(C_{0} Q_{10} 150+\right.$ Artemisia600) significantly increased the number of live cells compared to 6-OHDA cells $(P<0.05)$. Also, the $\mathrm{CoQ}_{10} 75+$ Artemisia200 concentration significantly increased $(P<0.001)$ compared to the other concentrations. The results of other concentrations were not dose-dependent and results showed the highest concentration had no significant effect.

A comparison of the effective concentration of $\mathrm{CoQ}_{10}$, Artemisia and their combination on cell viability is shown in Figure 5. The combined treated cells significantly increased the number of living cells compared to $\mathrm{CoQ}_{10}$ and Artemisia treated cells alone $(P<0.001)$. In addition, there was no significant difference between $\mathrm{CoQ}_{10}$ and Artemisia.

\section{Hoechst staining results}

To evaluate the nuclear density, Hoechst staining was used. According to the MTT assay results, the $200 \mu \mathrm{g} / \mathrm{ml}$ concentrations of Artemisia sieberi, $75 \mu \mathrm{M}$ concentration of $\mathrm{CoQ}_{10}$, and combination of $\mathrm{CoQ}_{10^{+}}$ Artemisia sieberi were used. As it is shown in Figures 6 , the apoptotic cells observed with the brilliant nuclei in 6-OHDA group cells more than antioxidant treatment groups. The percentage of apoptotic cells are shown in Figure 6A. The percentage of apoptotic cells in all oxidant treatment groups was significantly 


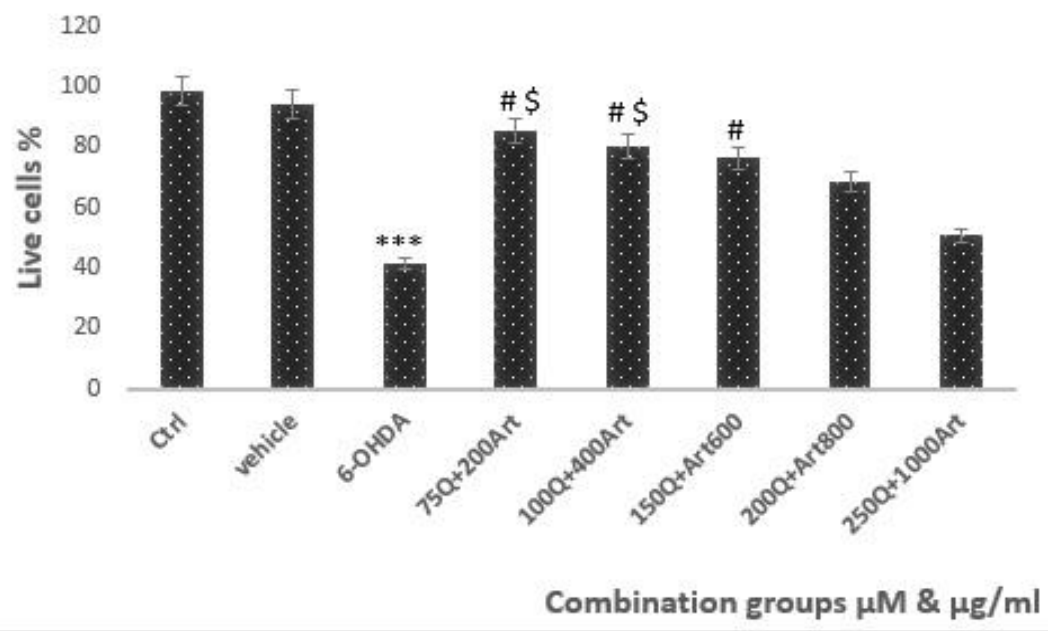

Fig.4. The viability of 6-hydroxydopamine (6-OHDA) treated cells under Artemisia and $\mathrm{CoQ}_{10}$ treatments. All experiments were performed in triplicate. ${ }^{\star \star \star} P<0.001$ significantly decreased viability compared to 6 -OHDA cells; ${ }^{\$} P<0.05$ significant differences at concentration of $(100+400),(75+200)$, with other concentrations; ${ }^{\#} P<0.001$ significant increased with 6 OHDA cells.

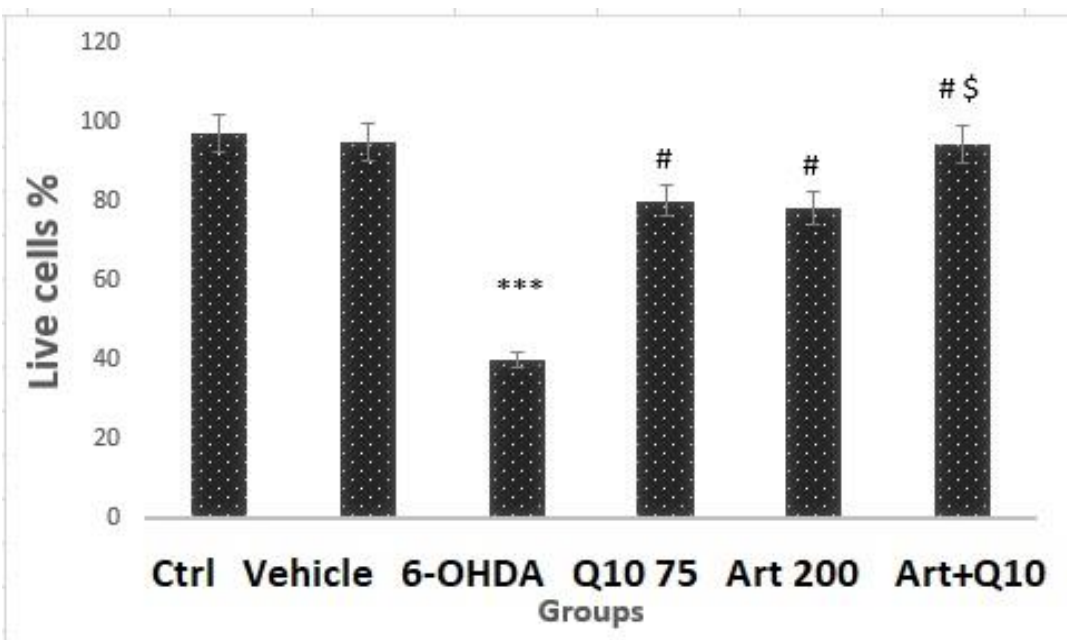

Fig.5. Comparison of the effective combination concentration in the viability of the 6-hydroxydopamine (6-OHDA) cells. All experiments were performed in triplicate and the data were considered as Mean \pm SEM. ${ }^{* * *} P<0.001$ significance decreased with the 6-OHDA; ${ }^{\#} P<0.01$ significantly increased the Artemisia200 compared with the 6 -OHDA; ${ }^{\$} P<0.05$ the significance of the combination of $75 \mu \mathrm{m} \mathrm{CoQ} 10$ and Artemisia sieberi $200 \mu \mathrm{g} / \mathrm{ml}$ treated cells compared each one alone.

lower than the 6-OHDA. Also, there was a significant decrease in the combination group in comparison to the $\mathrm{CoQ}_{10}$, and Artemisia groups $(P<0.01)$, and the Artemisia showed a significant decrease of apoptotic cells compared to the $Q_{10}$ group $(P<0.05$, Fig $6 \mathrm{~B})$.

\section{ROS assay results}

The evaluation ROS production showed that a combination of two antioxidants significantly inhibited the production of ROS compared to 6-OHDA treated cells and each antioxidant treatment alone $(P<0.01)$. The ROS production in Artemisia200 treated cells was significantly decreased in comparison with the $\mathrm{CoQ}_{10} 75 \mu \mathrm{M}$ treated cells $(P<0.05$, Fig. 7$)$.

\section{Results of P53 protein expression}

The expression of P53 according to Figure 8 showed that in the 6-OHDA group significantly increased compared to the control group $(P<0.001)$. The expression of P53 in the treated cells significantly decreased compared the 6-OHDA cells but, in the combination of two antioxidants, more significantly decreased compared with the 6-OHDA cells and each one alone $(P<0.001)$. Also, this data showed the P53 expression between the $Q_{10}$ and Artemisia groups was not significant.

\section{Discussion}

Parkinson's disease is a neurodegenerative disease 


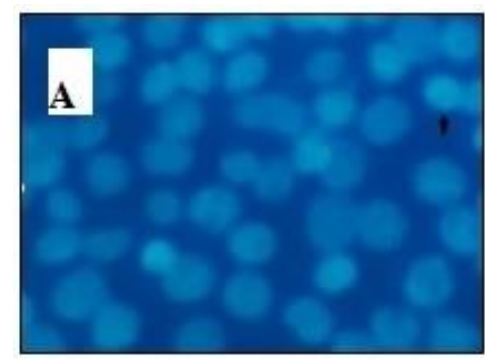

ctrl

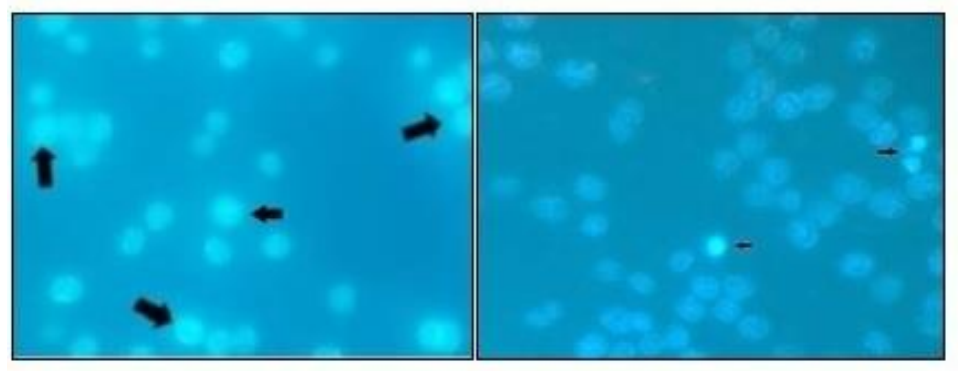

Artemisia $200 \mu \mathrm{g} / \mathrm{ml}$

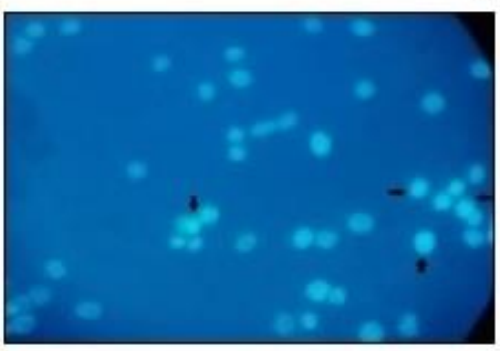

Artemisia \& Q10

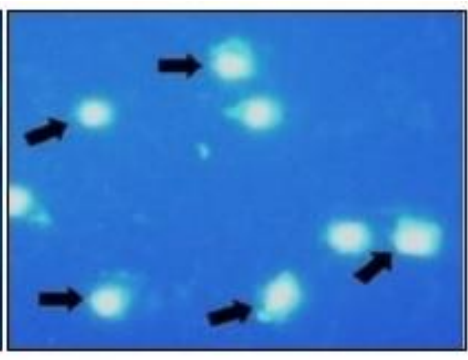

6-OHDA

Q10 $75 \mu \mathrm{M}$

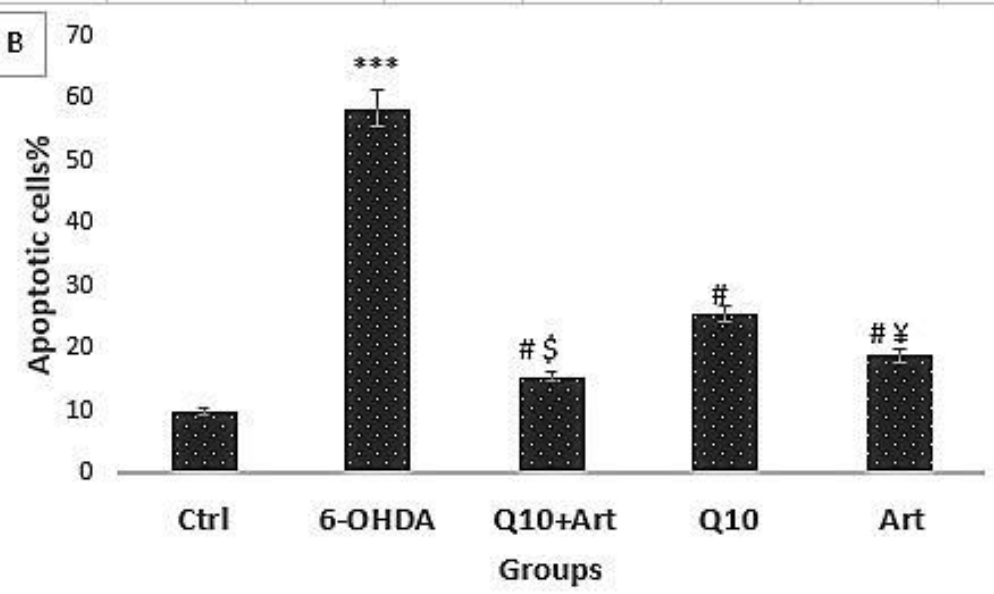

Fig.6. A: Hoechst staining of the treated cells using a fluorescence microscope at $400 x$ magnification with three repetitions. The arrows represent apoptotic nuclei. B: The comparison of apoptotic cells resulted in Hoechst 33342 staining (Mean \pm SEM). ${ }^{\prime \prime} P<0.001$ significantly increase the apoptotic cells in the 6-hydroxydopamine (6-OHDA) cells compared with the control group; ${ }^{\#} P<0.01$ the significantly decreased compared with $6-\mathrm{OHDA} ;{ }^{\$} P<0.05$ the significantly decreased compared to the Q10 and Artemisia treated cells; ${ }^{*} P<0.05$ significantly decreased compared with the $Q 10$ treated cells.

that affects motor, cognitive and emotional functions (Henchcliffe and Beal, 2008). The exact etiology of $\mathrm{PD}$ is still unknown and the role of oxidative stress in the pathophysiology of PD paid more attention recently. It is generally accepted that oxidative stress leads to mitochondrial dysfunction that in turns causes DNA damage and ultimately neuronal death. Despite advances in pathogenesis and pathophysiology of $\mathrm{PD}$, routine treatments are mostly symptomatic. During recent years, many types of research focused on the effectiveness of antioxidant agents with different origins. Among them, the CoQ10 


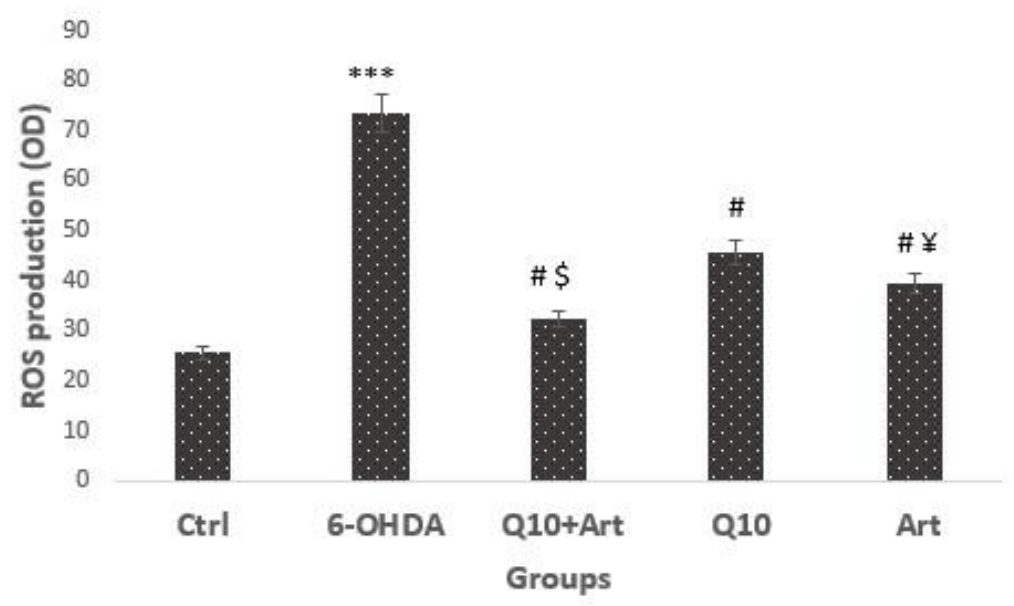

Fig.7. Represented ROS production between groups. All experiments were performed in triplicate and the data were considered as Mean \pm SEM. ${ }^{* * *} P<0.01$ significant increase 6-hydroxydopamine (6-OHDA) compared with the control; ${ }^{\#} P<0.01$ significantly decrease antioxidants treated cells in comparison with the 6 -OHDA cells; ${ }^{\$} P<0.05$ significantly decrease in the combination group with two treatment groups; ${ }^{*} P<0.05$ significant decrease compared with CoQ10.

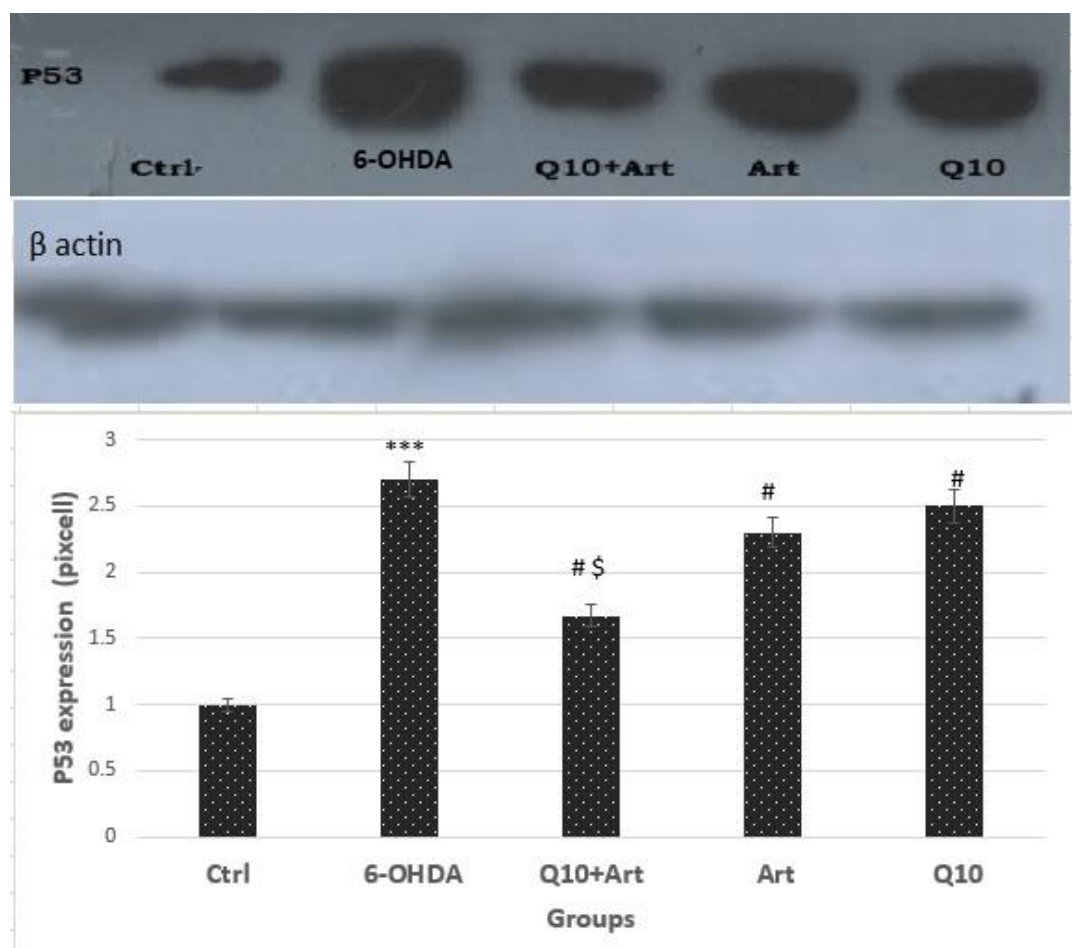

Fig.8. Represented the expression of $p 53$ protein by western blotting assay (three times). ${ }^{* * t} P<0.001$ significantly increased compared with the control group; ${ }^{\#} P<0.01$ significantly decreased compared to 6 -hydroxydopamine (6-OHDA) cells; ${ }^{\$} P<0.05$ significance between groups.

has received more attention. Loganathan et al. (2013) showed the dose-dependent protective effects of CoQ10 on MDA-MB-468 and BT549 cell lines. Seifried et al. (2007) reported the protective effect of CoQ10 on a variety of cells, they also showed that CoQ10 has the potential to reduce Parkinson's and Alzheimer's symptoms by reducing oxidative stress. Additionally, herbal extracts with antioxidant properties seem to be useful in the treatment of certain neurodegenerative diseases. In the present study, $75 \mu \mathrm{M}$ dose of CoQ10 was the most effective dose increasing viability in the PD cellular model compared to the other concentration. Li et al. showed that $100 \mu \mathrm{m}$ of CoQ10 could protect the SHSY5Y cells against the beta-amyloid neurotoxin peptide and inhibit cell death (Li et al., 2005) and they described CoQ10 as a compound promoting antioxidant defense capacity and the activity of antioxidant 
enzymes is able to ( $\mathrm{Li}$ et al., 2016). Moreover, da Silva Machado et al. (2013) reported that 0.1, 0.5 and $1 \mu \mathrm{g} / \mathrm{ml}$ concentration of CoQ10 prevent DNA damage against neurotoxin cisplatin in PC12 cells. Regarding Artemisia, there are some reports that indicate its antioxidant properties. Shoaib et al. (2015) showed that the Artemisia Macrocephala is able to inhibit the activity of butyrylcholinesterase and acetylcholinesterase enzymes, which are effective to treat certain neurodegenerative diseases. Choi et al. (2013) extracted the phenolic compounds in the hydro alcoholic extract of the Artemisia persica and reported the high antioxidant capacity of these compounds. In another study by Poiata et al. (2009) showed that the aqueous extract of the Artemisia Species Afra Jacy reduced malondialdehyde, while increased superoxide dismutase and glutathione peroxidase, which inhibit the oxidative effect of hydrogen peroxide. Zeng et al. (2014) in their study reported that DSF-52 an extract from Artemisia Argyi affects the microglia cells and inhibits the inflammatory and nitric oxide the response of these cells in neurodegenerative diseases. Hong and Lee (2009) showed that ethyl acetate in Artemisia capillaris, as ROS inhibitor, not only protects V79 cell line against hydrogen peroxide but also increases the activity of antioxidant enzymes such as superoxide dismutase, glutathione peroxidase and catalase as well as prevent lipid peroxidation. Kaur et al. (2012) reported also the same property in Artemisia scoparia, they had attention to the essential oils of Artemisia scoparia as a strong ROS-inhibiting defense mechanism that inhibits the hydrogen peroxide activity. Also, in the research in 2019 the protective different ethyl acetate and total flavonoids extracts of Artemisia ciniformis against H202 toxicity evaluated. Their results showed the ethyl acetate extract had the most effective on suppressing the toxicity of $\mathrm{H} 2 \mathrm{O} 2$ and $\mathrm{A}$. ciniformis is a potential choice for preventing different neurodegenerative diseases (Hosseinzadeh et al., 2019). The results of our study of using CoQ10 and Artemisia sieberi separately are in line with the aforementioned studies and confirmed their antioxidant and anti-apoptotic properties. Although the species of Artemisia that we used in our study are different from the species used by other researchers, it seems that all the species of Artemisia have the same effective extraction with almost similar properties. Additionally, our results showed better effects of CoQ10 than Artemisia. This finding might be due to using the total extract of Artemisia instead of its effective component, Artemisinin. Thus, it seems the better results for the combination use of Artemisia and CoQ10 are related mainly to CoQ10 activity than Artemisia. It is also possible that CoQ10 and Artemisia act synergistically via similar or different pathways. Beneficial clinical effects of CoQ10 showed in many studies, these effects of CoQ10 could happen via different mechanisms. Among this mechanism, immune modulation and enzymatic rebalance properties of CoQ10 have received more attention. Soleimani et al. (2014) reported the effect of $\mathrm{CoQ} 10$ on the ratio of $\mathrm{TH} 1 / \mathrm{TH} 2$ in the experimental autoimmune encephalomyelitis model of multiple sclerosis. Fuller et al. (2006) reported that CoQ10 could suppress the increased production of certain inflammatory mediators such as IL-6. In addition to the mentioned mechanism, it has been shown that CoQ10 exerts/has synergistic effects when combined with certain drugs in patients with cancer (Premkumar et al., 2007). It has been generally accepted that CoQ10 not only produces sub-cellular energy but also acts as an antioxidant that prevents lipid peroxidation and scavenges superoxide anions. CoQ10 can be diffused within the biological membrane and it can leak out the inner membrane of mitochondria (Fuller et al., 2006). Nacetyl cysteine, a known antioxidant, can block the effects of TNF- $\alpha$ in HeLa cells. It acts via interaction with kinases involved in the cellular signaling pathway (Cammer, 2002). Unlike CoQ10, the exact action mechanisms of Artemisia are still unknown. In order to answer the questions regarding the effects of Artemisia and its mechanisms, we are going to examine the role of its effective extract known as Artemisinin in upcoming projects. However, we believe that Artemisia also acts in a similar way to the CoQ10.

\section{Conclusion}

Based on our findings, the combination of agents with antioxidant and anti-apoptotic properties with consideration of the using concentration could have better therapeutic results. More studies need to show exact mechanisms of action.

\section{Acknowledgments}

The authors are deeply grateful to colleagues and 
laboratory staff of NRC/IUMS for their sincere collaboration and also Vice Chancellor of Research and Technology. The present research supported by the Neuroscience Research Center (NRC) of Iran University of Medical Science and Islamic Azad University Karaj Branch.

\section{Conflict of interest}

The authors declare no conflict of interest.

\section{References}

Bora KS, Sharma A. Neuroprotective effect of Artemisia absinthium $L$. on focal ischemia and reperfusioninduced cerebral injury. J Ethnopharmacol 2010; 129: 403-9. https://doi.org/10.1016/j.jep.2010.04.030

Cameán AM, Ruiz-Cabello ML, Gutiérrez-Praena D, Pichardo S, Jos A, Puerto M, et al. Study of the basal cytotoxicity and the oxidative stress induction of carvacrol, thymol, and their mixture in the human cell line Caco-2. Toxicol Lett 2013: S119. https://doi.org/ 10.1016/j.toxlet.2013.05.206

Cammer W. Protection of cultured oligodendrocytes against tumor necrosis factor- $\alpha$ by the antioxidants coenzyme Q10 and N-acetyl cysteine. Brain Res Bull 2002; 58: 587-92. https://doi.org/10.1016/S0361-9230(02)00830-4

Choi E, Park H, Lee J, Kim G. Anticancer, antiobesity, and anti-inflammatory activity of Artemisia species in vitro. $\mathrm{J}$ Tradit Chin Med 2013; 33: 92-7. https://doi.org/ 10.1016/S0254-6272(13)60107-7

da Silva Machado C, Mendonça LM, de Paula Venancio V, Bianchi ML, Antunes LM. Coenzyme Q10 protects Pc12 cells from cisplatin-induced DNA damage and neurotoxicity. Neurotoxicology 2013; 36: 10-6. https://doi.org/10.1016/j.neuro.2013.02.004

Fuller B, Smith D, Howerton A, Kern D. Anti-inflammatory effects of CoQ10 and colorless carotenoids. J Cosmet Dermatol 2006; 5: 30-8. https://doi.org/10.1111/j.14732165.2006.00220.x

Gordanian B, Behbahani M, Carapetian J, Fazilati M. In vitro evaluation of cytotoxic activity of flower, leaf, stem and root extracts of five Artemisia species. Res Pharm Sci 2014; 9: 91.

Henchcliffe C, Beal MF. Mitochondrial biology and oxidative stress in Parkinson disease pathogenesis. Nat Rev Neurol 2008; 4: 600-9. https://doi.org/10.1038/ ncpneuro0924

Hirtz D, Thurman D, Gwinn-Hardy K, Mohamed M, Chaudhuri A, Zalutsky R. How common are the "common" neurologic disorders? Neurology 2007; 68: 326-37. https://doi.org/10.1212/01.wnl.0000252807. 38124.a3

Hong JH, Lee IS. Cytoprotective effect of Artemisia capillaris fractions on oxidative stress-induced apoptosis in V79 cells. Biofactors 2009; 35: 380-8. https://doi.org/10.1002/biof.35

Hosseinzadeh L, Mirzaei S, Hajialyani M, Ahmadi F, Emami
SA, Mojarrab M. The protective effect of different extracts of aerial parts of Artemisia ciniformis against $\mathrm{H} 2 \mathrm{O} 2$-induced oxidative stress and apoptosis in PC12 pheochromocytoma cells. J Appl Pharm 2019; 9: 16-23. https://doi.org/10.7324/JAPS.2019.90403

Jameie SB, Masoumipoor M, Janzadeh A, Nasirinezhad F, Kerdari M, Soleimani M. Combined therapeutic effects of low power laser (980nm) and CoQ10 on Neuropathic Pain in adult male rat. Med J Islam Repub Iran 2014; 28: 58.

Kaur S, Singh HP, Batish DR, Kohli RK. Artemisia scoparia essential oil inhibited root growth involves reactive oxygen species (ROS)-mediated disruption of oxidative metabolism: In vivo ROS detection and alterations in antioxidant enzymes. Biochem Syst Ecol 2012; 44: 3909. https://doi.org/10.1016/j.bse.2012.06.015

Lee SJ, Chung HY, Lee IK, Oh SU, Yoo ID. Phenolics with inhibitory activity on mouse brain monoamine oxidase (MAO) from whole parts of Artemisia vulgaris $L$ (Mugwort). Food Sci Biotechnol 2000; 9: 179-82.

Li G, Zou LY, Cao CM, Yang ES. Coenzyme Q10 protects SHSY5Y neuronal cells from beta amyloid toxicity and oxygen-glucose deprivation by inhibiting the opening of the mitochondrial permeability transition pore. Biofactors 2005; 25: 97-107. https://doi.org/10.1002/ biof.5520250111

Li L, Du J, Lian Y, Zhang Y, Li X, Liu Y, et al. Protective effects of coenzyme $Q 10$ against hydrogen peroxideinduced oxidative stress in PC12 cell: the role of Nrf2 and antioxidant enzymes. Cell Mol Neurobiol 2016; 36: 103-11. https://doi.org/10.1007/s10571-015-0224-4

Lipski J, Nistico R, Berretta N, Guatteo E, Bernardi G, Mercuri NB. L-DOPA: a scapegoat for accelerated neurodegeneration in Parkinson's disease? Prog Neurobiol 2011; 94: 389-407. https://doi.org/10.1016/ j.pneurobio.2011.06.005

Loganathan R, Selvaduray KR, Nesaretnam K, Radhakrisnan A. Differential and antagonistic effects of palm tocotrienols and other phytonutrients (carotenoids, squalene and coenzyme Q10) on breast cancer cells in vitro. J Oil Palm Res 2013; 25: 208-15.

Mojarab M, Emami SA, Hassanzadeh-Khayyat $M$. Antioxidant activity of methanol extracts of different species of Artemisia from Iran. Pharmacologyonline 2009; 2: 797-807.

Muto T, Watanabe T, Okamura M, Moto M, Kashida Y, Mitsumori K. Thirteen-week repeated dose toxicity study of wormwood (Artemisia absinthium) extract in rats. J Toxicol Sci 2003; 28: 471-8. https://doi.org/10.2131/ jts. 28.471

Poiată A, Tuchiluş C, Ivănescu B, Ionescu A, Lazăr M. Antibacterial activity of some Artemisia species extract. Rev Med Chir Soc Med Nat lasi 2009; 113: 911-4.

Premkumar VG, Yuvaraj S, Vijayasarathy K, Gangadaran SGD, Sachdanandam P. Serum cytokine levels of interleukin-1 $\beta,-6,-8$, tumour necrosis factor- $\alpha$ and vascular endothelial growth factor in breast cancer patients treated with tamoxifen and supplemented with Co-Enzyme Q10, riboflavin and niacin. Basic Clin 
Pharmacol Toxicol 2007; 100: 387-91. https://doi.org/ 10.1111/j.1742-7843.2007.00065.x

Seifried HE, Anderson DE, Fisher El, Milner JA. A review of the interaction among dietary antioxidants and reactive oxygen species. J Nutr Biochem 2007; 18: 567-79. https://doi.org/10.1016/j.jnutbio.2006.10.007

Shah M, Rajagopalan S, Xu L, Voshavar C, Shurubor Y, Beal $F$, et al. The high-affinity D2/D3 agonist D512 protects PC 12 cells from 6-OHDA-induced apoptotic cell death and rescues dopaminergic neurons in the MPTP mouse model of Parkinson's disease. J Neurochem 2014; 131: 74-85. https://doi.org/10.1111/ jnc. 12767

Shoaib M, Shah I, Ali N, Shah SW. In vitro acetylcholinesterase and butyrylcholinesterase inhibitory potentials of essential oil of Artemisia macrocephala. Bangladesh J Pharmacol 2015; 10: 8791. https://doi.org/10.3329/bjp.v10i1.21171

Singh N, Pillay V, Choonara YE. Advances in the treatment of Parkinson's disease. Prog Neurobiol 2007; 81: 29-44. https://doi.org/10.1016/j.pneurobio.2006.11.009

Soleimani M, Jameie SB, Barati M, Mehdizadeh M, Kerdari M. Effects of Coenzyme Q10 on the ratio of $\mathrm{TH} 1 / \mathrm{TH} 2$ in experimental autoimmune encephalomyelitis model of multiple sclerosis in C57BL/6. Iran Biomed J 2014; 18: 203.

Zeng KW, Wang S, Dong X, Jiang Y, Tu PF. Sesquiterpene dimer (DSF-52) from Artemisia argyi inhibits microgliamediated neuroinflammation via suppression of NF-kB, JNK/p38 MAPKs and Jak2/Stat3 signaling pathways. Phytomedicine 2014; 21: 298-306. https://doi.org/ 10.1016/j.phymed.2013.08.016 